\title{
ANALISIS PENYERAPAN ENERGI CRASH BOX POLA ORIGAMI PADA PENGUJIAN FRONTAL IMPACT POSISI ANGULAR FRONTAL
}

\author{
Redi Bintarto ${ }^{1}$, Andik Atmaja², Imam Kusyairi3 \\ 1, 2, 3 Politeknik Kota Malang \\ Jl. Raya Tlogowaru No. 3 Kedungkandang Malang \\ E-mail: redibintarto@gmail.com
}

\begin{abstract}
In the car, the body structure is designed in such a way so as to transfer and absorb energy. This serves to minimize the result of this accident related to kinetic energy. This needs a system to absorb the kinetic energy maximally, so as a result of a frontal collision events that can be reduced optimally and kinetic energy can be absorbed by a front body structure. Devices used for absorbing kinetic energy in the car is usually called a crash box, which is located between the main structure and bumper. Crash Box generally tubular thin shaped. It has been a lot of research about the crash box. In this study using crash box origami patterns and using methods taguchi orthogonal array L9 (34). AA7003-T7 aluminum material modeled as bilinear isotropic hardening, the loading method is Frontal Impact Frontal Angular Position with impact angles of 5, 15 and 30 degree by using the finite element software simulation methods. The simulation results showed that the crash box in the lowest possible energy absorption were happened at crash box with 5 degree, with 683153 Joule energy absorbsion. The highest result was happened to crash box number 5 with the results of 3,140.778 Joule. Lowest absorption on impact of 15 degree and 30 degree were happened to crash box number 1 and number 3 with a value of 245685 Joule and 174845 Joule, while the highest absorption at mumber 3 with each value 1,708.521 Joule and 1,750.872 Joule.
\end{abstract}

Keywords: Crash Box, Origami, Angular Frontal, energy absorbed.

\section{PENDAHULUAN}

World Health Organization (WHO) merilis sebuah laporan yang berjudul The Global Report on Road Safety 2015, Laporan ini berisi tentang kecelakaan lalu lintas pada 180 negara. Dalam laporan ini menempatkan Indonesia menduduki posisi ketiga di Asia dalam hal angka kematian akibat kecelakaan, setelah China dan India dengan total 38.279. Walaupun Indonesia menduduki peringkat ketiga, namun jika dilihat dari prosentasi data statistic dari jumlah penduduk, Indonesia menempati peringkat pertama dengan angka kematian 0,015\%, dibawah China dengan prosentase 0,018\% dan India 0,017\% [1].

Peningkatan kepadatan lalu lintas yang menyebabkan kecelakaan lalu lintas semakin meningkat, hal inilah yang menyebabkan para pembuat kebijakan menjadikan keselamatan adalah hal yang wajib diperhatikan dan dijadikan riset utama di bidang teknik kendaraan. Bidang perhatian khusus adalah desain crashworthiness (ketahanan benturan) mobil. Mobil diharuskan lulus tes kecelakaan yang dikeluarkan oleh pihak berwenang. Pada mobil, struktur bodi dirancang sedemikian rupa agar mentransfer dan menyerap energi. Hal ini berfungsi untuk meminimalisasi akibat kecelakaan ini berkaitan dengan energi kinetik. Dan memerlukan sistem untuk menyerap energi kinetik sepelan mungkin, agar akibat dari kejadian tabrakan frontal yang dapat dikurangi secara optimal dan energi kinetik dapat diserap oleh struktur depan bodi.

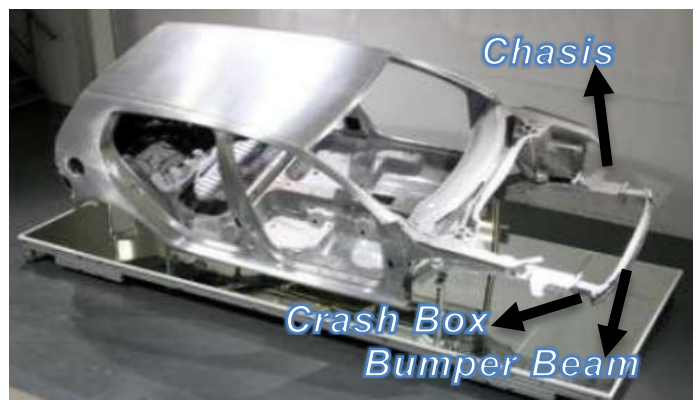

Gambar 1 Letak Crash Box, Bumper dan Chasis

Perangkat yang digunakan untuk menyerap energi kinetik pada mobil biasanya 
disebut crash box, yang terletak antara struktur utama dan bumper sebagaimana terlihat pada Gambar 1. Crash Box pada umumnya berbentuk tabung berdinging tipis. Telah banyak penelitian tentang crash box, seperti mempelajari tumbukan tabung persegi dengan dua pola yang dibangun menggunakan elemen piramida, dimana energi yang diserap meningkat $15-33 \%$ dan $54-93 \%$, pada masingmasing bentuk gaya aksial yang menghancurkan karakteristik gaya longitudinal tabung persegi diteliti secara numerik. Penyerapan energi meningkat hingga 92\% dan kekuatan puncak berkurang hingga $22 \%$, dibandingkan dengan tabung persegi dengan bentuk konvensional [2].

Perkembangan saat ini, penelitian tentang crash box mengarah kepada pengembangan pola origami. Crash box pola origami menunjukkan ciri - ciri remukan (collapse) yang diprediksi dan stabil, dengan penyerapan energi yang meningkat mencapai $92,1 \%$ dalam kasus yang optimal (optimum case) [3].

Penelitian tentang pengembangan pola origami juga dilakukan dengan metode taguchi terdiri dari empat faktor, dan faktor yang paling mempengaruhi kemampuan penyerapan energi adalah, tebal ( $\mathrm{t})$, jumlah segmen $(\mathrm{M} / \mathrm{l})$, jarak antar cekungan (b) dan panjang cekungan (c). Dari latar belakang inilah diperlukan penelitian lebih lanjut mengenai penyerapan energi crash box pola origami pada pengujian Front Impat posisi angular frontal dengan berbagai sudut. Selain itu dapat ditentukan perilaku deformasi dari crash box yang optimal dalam penyerapan energi yang lebih besar [4].

\section{METODOLOGI PENELITIAN}

Gambar 2 menunjukkan model crash box pola origami yang diteliti pertama kali oleh Zhang, $X$., dan You, Z.
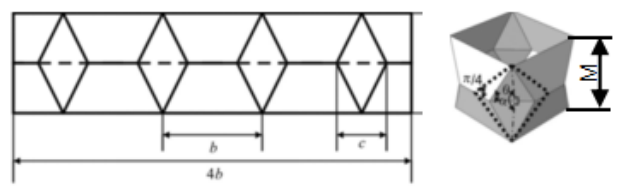

Gambar 2 Desain Crash Box Pola Origami
Penelitian ini menggunakan metode taguchiorthogonal array L9 (34) dan 9 model crash box pola origami akan didesain.

Dengan:

\section{c :Panjang cekungan}

b : :lebar antar cekungan

t :tebal

M : jumla (b) zgmen (satuan) : panjang sisi $(\mathrm{mm})$

Material yang digunakan pada penelitian ini adalah aluminium AA7003-T7, yang mempunyai sifat mekanis :

$\begin{array}{lll}\text { Density }\left(\mathrm{kg} / \mathrm{m}^{3}\right) & : & 2771 \\ \text { Poisson's Ratio } & : & 0.33 \\ \text { Young Modulus (GPa) } & : & 71 \\ \text { Yield Strength (MPa) } & : & 247 \\ \text { UTS (MPa) } & : & 291 \\ \text { Tangent Modulus (GPa) } & : & 0.5\end{array}$

Material diatas dimodelkan sebagai bilinier isotropic hardening, dimana sebuah material mengalami deformasi elastis yang berlanjut menjadi deformasi plastis. Ketika terjadi impact material mengalami deformasi. Model pembebanan pada penelitian ini terlihat sebagaimana gambar 3 , dengan sudut kontak crash box pola origami kepada impactor masing - masing sebesar $5^{0}, 15^{\circ}$ dan $30^{\circ}$.

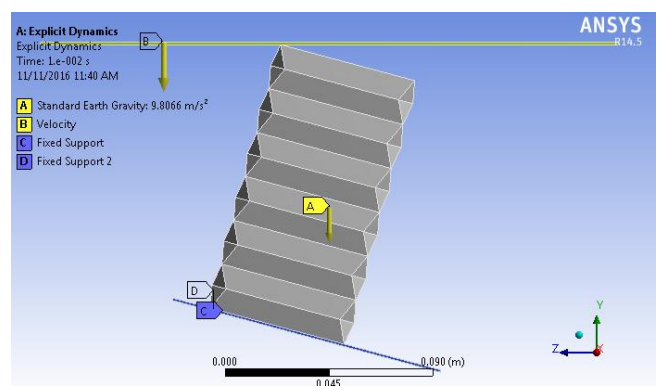

Gambar 3 Pemodelan pembebanan pada crash box pola origami

Pengujian pada penelitian ini adalah dengan simulasi quasistatic testing, yaitu Impactor akan bergerak ke sumbu -Y deggan kecepatan 16 $\mathrm{km} / \mathrm{jam}$, dari pergerakan impactor tersebut akan menumbuk crash box dan akan menghasilkan deformasi plastis, perubahan yang terjadi sebagai data penyerapan energi. 


\section{HASIL DAN PEMBAHASAN \\ Energi Yang Diserap}

Berikut merupakan hasil simulasi dari pengujian yang dilakukan dengan Software Elemen Hingga, data yang didapatkan berupa deformasi dan force reaction masing-masing data tersebut akan dibandingkan untuk mengetahui crash box dengan penyerapan energi terbesar.

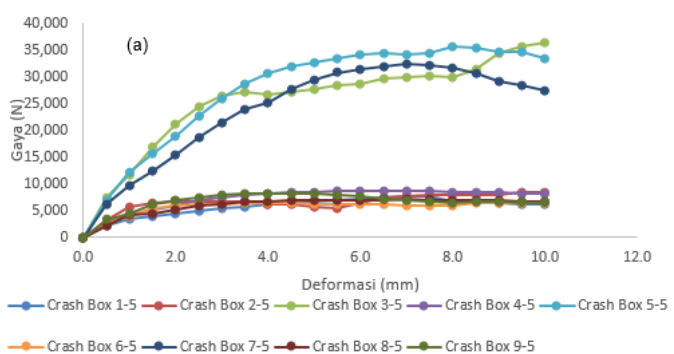

(b)

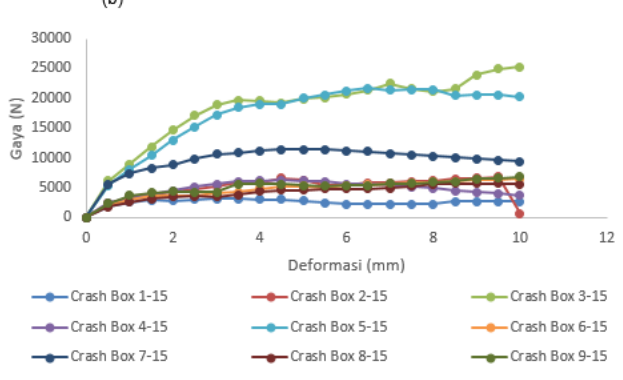

(c)

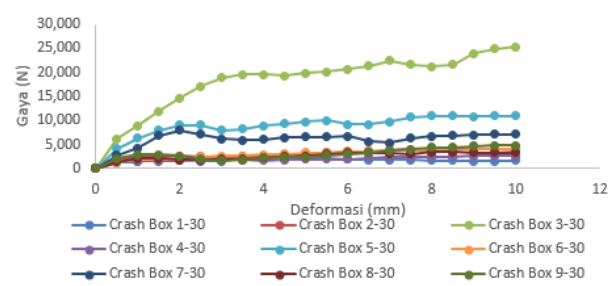

Gambar 4 Gaya kontak pada Crash Box pola Origami, (a) $5^{\circ}$, (b) $15^{\circ}$ dan (c) $30^{\circ}$

Pada saat impactor jatuh menumbuk crash box pola origami maka keduanya saling memberikan gaya yang disebut dengan gaya kontak, gaya yang diberikan impactor pada crash box nantinya akan dikalikan dengan deformasi maksimal yang terjadi sehingga akan diketahui besar energi yang diserap oleh crash box. Perbedaan hasil pada gaya reaksi crash box lebih disebabkan karena crash box sudah tidak memilikii bentuk yang sama dengan kondisi sebelum pembebanan. Fenomena ini bisa dijelaskan lebih lanjut dengan melihat hasil simulasi berupa grafik hubungan perpindahan dengan gaya pada Gambar 4.

\section{Dengan:}

$$
U=W=\int_{0}^{\delta} P(\delta) d \delta
$$

$$
\begin{array}{ll}
U & =\text { Energi Regangan }(\mathrm{J}) \\
W & =\text { Energi }(\mathrm{J}) \\
P & =\text { Beban }(\mathrm{N}) \\
\delta & =\text { Deformasi }(\mathrm{m})
\end{array}
$$

Rumus 1 digunakan untuk menghitung besarnya energi yang diserap oleh crash box saat terjadi deformasi, energy regangan pada Gambar 4 dapat dihitung dari luasan dibawah grafik gaya dan deformasi. Berdasarkan perhitungan luas daerah dibawah grafik diperoleh nilai energi yang diserap, hal ini ditunjukkan pada Tabel 1.

Dari data dalam Tabel 1 diperoleh hasil bahwa crash box terendah dalam penyerapan energi pada crash box dengan impact 5 derajat adalah crash box nomor 1 dengan hasil 683.153 Joule dan tertinggi pada crash box point 5 dengan hasil $3,140.778$. Penyerapan terendah pada impact $15^{\circ}$ dan $30^{\circ}$ derajat masing - masing adalah adalah crash box poin 1 dan 3 dengan nilai $245.685 \mathrm{~J}$ dan $174.845 \mathrm{~J}$, adapun penyerapan tertinggi pada point 3 dengan masing - masing nilai $1,708.521 \mathrm{~J}$ dan $1,750.872 \mathrm{~J}$.

Tabel 1 Energi yang diserap pada setiap

\begin{tabular}{lrrr}
\multicolumn{4}{c}{ variasi diameter dan panjang crash box. } \\
\multicolumn{1}{l}{$\mathbf{5}^{\circ}(\mathbf{J})$} & \multicolumn{1}{c}{$\mathbf{1 5 ^ { \circ } ( \mathbf { J } )}$} & \multicolumn{1}{c}{$\mathbf{3 0 ^ { \circ } ( \mathbf { J } )}$} \\
\hline CB 1 & 683.153 & 245.685 & 183.517 \\
\hline CB 2 & 783.061 & 487.018 & 281.171 \\
\hline CB 3 & 2905.839 & 1708.521 & 1750.872 \\
\hline CB 4 & 853.774 & 454.493 & 174.845 \\
\hline CB 5 & 3140.778 & 1617.289 & 847.362 \\
\hline CB 6 & 685.073 & 442.201 & 293.808 \\
\hline CB 7 & 2701.098 & 909.845 & 583.491 \\
\hline CB 8 & 762.3 & 392.423 & 247.145 \\
\hline CB 9 & 763.752 & 464.932 & 291.75 \\
\hline
\end{tabular}

Dari data dalam Tabel 1 diperoleh hasil bahwa crash box terendah dalam penyerapan 
energi pada crash box dengan impact 5 derajat adalah crash box nomor 1 dengan hasil 683.153 Joule dan tertinggi pada crash box point 5 dengan hasil 3,140.778. Penyerapan terendah pada impact $15^{\circ}$ dan $30^{\circ}$ derajat masing - masing adalah adalah crash box poin 1 dan 3 dengan nilai $245.685 \mathrm{~J}$ dan $174.845 \mathrm{~J}$, adapun penyerapan tertinggi pada point 3 dengan masing - masing nilai 1,708.521 J dan 1,750.872 J.

\section{Pengaruh luas penampang terhadap penyerapan energi}

Luasan penampang pada crash box pola origami berpengaruh terhadap kemampuan penyerapan energi, semakin besar luasan penampang maka semakin besar pula kemampuan penyerapan energi pada crash box, hal ini terlihat pada Tabel 2. Gambar 5 menunjukkan trend peningkatan kemampuan penyerapan energi, hal ini linier dengan grafik momen inertia pada Gambar 6. Pada tabel bisa disimpulkan bahwa nilai penyerapan energi terendah terjadi pada crash box 1 dan tertinggi pada crash box 3 .

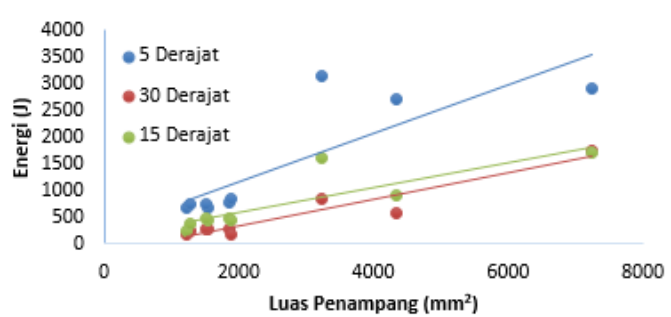

Gambar 5 Grafik Hubungan Luas Penampang dengan energi yang diserap

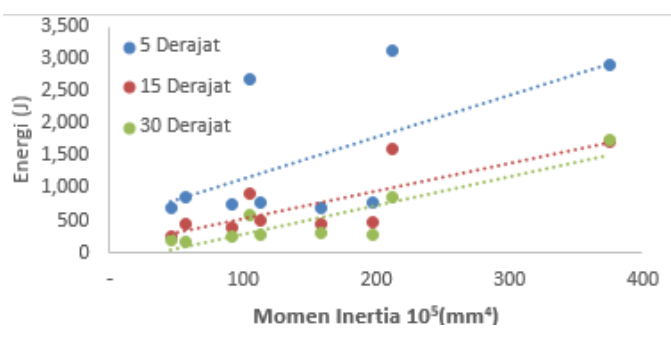

Gambar 6 Grafik Hubungan Momen Inertia dengan energi yang diserap

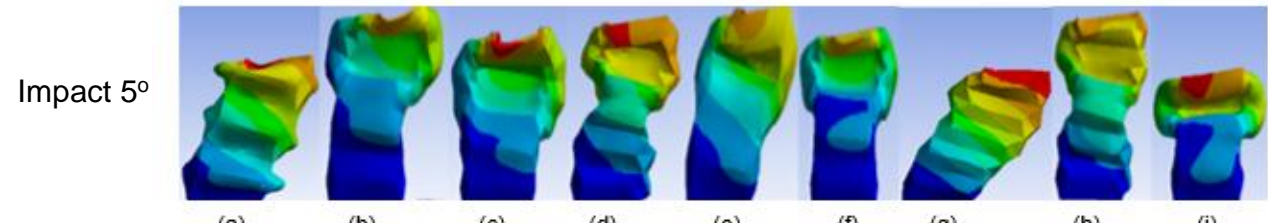

(a)

(b)

(c)

(d)

(e)

(g)

(h)

(i)

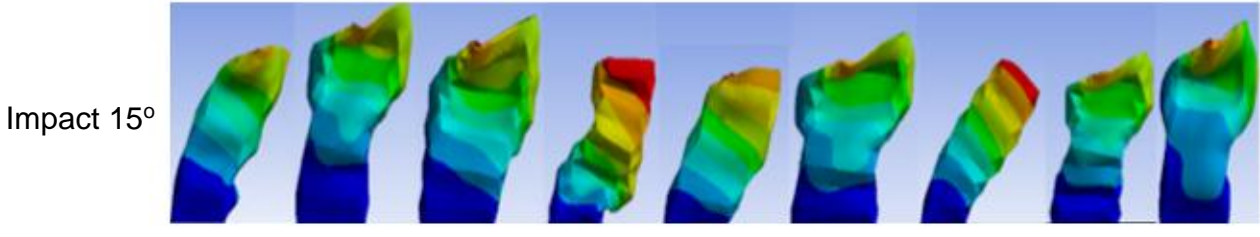
(a')
(光)
$\left(\mathbb{G}^{\prime}\right)$
(d')
(e')
(f) $\quad\left(\mathrm{g}^{\prime}\right)$
(h')
(I')

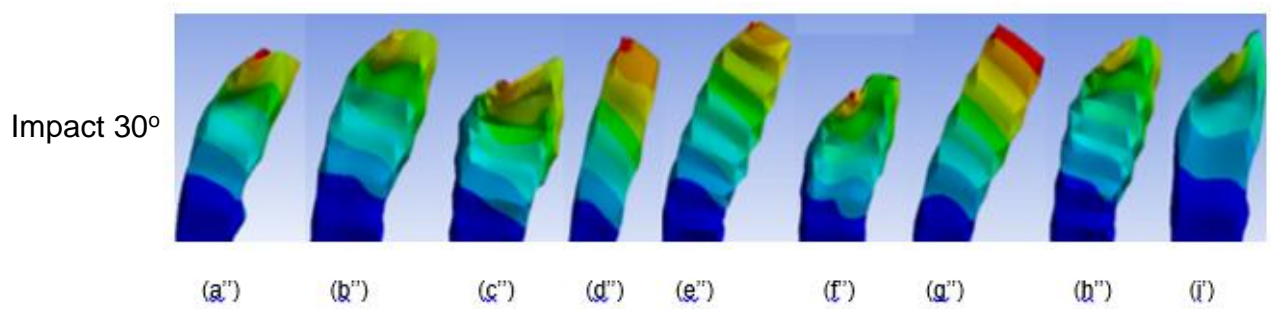

Gambar 7 (a, a', a") crash box 1, (b, b', b") crash box 2, (c, c', c") crash box 3, (d, d', d") crash box 4, (e, e', e") crash box 5, (f, f', f") crash box 6, (g, g', g') crash box 7, (h, h', h") crash box 8, (l, l', l') crash box 9 
Tabel 2 Tabel Luas Penampang dan hasil energi yang diserap

\begin{tabular}{lllll}
\hline Nama & $\begin{array}{c}\text { Penampang } \\
\left(\mathbf{m m}^{2}\right)\end{array}$ & $\mathbf{5}^{\mathbf{0}} \mathbf{( J )}$ & $\mathbf{1 5}^{\mathbf{0}} \mathbf{( J )}$ & $\mathbf{3 0}^{\mathbf{0}}(\mathbf{J})$ \\
\hline CB 1 & 1215.86 & 683.15 & 245.69 & 183.52 \\
\hline CB 2 & 1854.38 & 783.06 & 487.02 & 281.17 \\
\hline CB 3 & 7247.83 & 2905.84 & 1708.52 & 1750.87 \\
\hline CB 4 & 1872.23 & 853.77 & 454.49 & 174.85 \\
\hline CB 5 & 3229.35 & 3140.78 & 1617.29 & 847.36 \\
\hline CB 6 & 1545.44 & 685.07 & 442.20 & 293.81 \\
\hline CB 7 & 4329.35 & 2701.10 & 909.85 & 583.49 \\
\hline CB 8 & 1264.59 & 762.30 & 392.42 & 247.15 \\
\hline CB 9 & 1516.32 & 763.75 & 464.93 & 291.75 \\
\hline
\end{tabular}

\section{Pengaruh Momen Inertia}

$$
k=\frac{3 E I}{L^{3}}
$$

Keterangan:

$K=$ Kekakuan $(\mathrm{N} / \mathrm{m})$

$\delta=$ Perpindahan akibat deformasi $(m)$

$E=$ Modulus elastisitas material $\left(\mathrm{N} / \mathrm{m}^{2}\right)$

$I=$ Momen inersia luasan penampang $\left(\mathrm{m}^{4}\right)$

$L=$ Panjang $(m)$

Rumus 2 merupakan rumus kekakuan tersebut, dapat disimpulkan bahwa semakin besar momen inersia luasan penampang maka kekakuan semakin meningkat. Hal ini sesuai dengan yang terlihat pada Gambar 6 yang memperlihatkan trend peningkatan energi yang diserap seiring bertambahnya momen inertia. Crash box dengan penyerapan energi terendah terjadi pada crash box pola 1 dan tertinggi crash box pola 3 .

\section{Pola Deformasi}

Berdasarkan pengamatan visual pada gambar 7 terlihat crash box pola origami mengalami berbagai macam deformasi. Secara keseluruhan pola deformasi pada crash box pola origami di dominasi oleh buckling dan adanya lekukan - lekukan pola aksial. Hal ini dikarenakan arah beban impak yang frontal namun posisi crash box pola origami miring, sehingga menimbulkan momen yang diterima oleh crash box dan menyebabkan crash box mengalami tekanan pada dindingnya. Pola pre folded pada crash box pola origami dapat berfungsi menahan beban impact, walaupun kondisi crash box pola origami miring namun pola pre folded dapat menyalurkan energi impact. Pada gambar 7 adalah hasil simulasi software elemen hingga, dengan posisi crash box sebelumnya miring dibuat tegak agar bisa mengetahui pola deformasi dan terjadi buckling ataukah tidak. Sebagaimana terlihat pada gambar 7 , crash box pola origami dengan posisi 5 derajat dari impactor terdapat bukling keseluruhan pada crash box point (a) (d) (e) (g) dan (h), dan pada crash box pola origami (b), (c) (f) dan (i) mengalami bukling sebagian, hal ini terlihat pada struktur bagian bawah crash box masih bertahan ketika terjadi impact. Pada crash box pola origami dengan posisi 15 derajat dari impactor terdapat bukling sebagian pada gambar 7 point b', dan bukling keseluruhan pada point (a'), (c'), (d'), (e'), (f'), ( $\left.g^{\prime}\right),\left(h^{\prime}\right)$ dan (i'). Pada crash box pola origami dengan posisi 30 derajat dari impactor terdapat bukling ling keseluruhan pada point (a"), (b") (c"), (d"), (e"), (f"), (g"), (h") dan (i").

Namun jika diamati lebih lanjut pola deformasi pada crash box pola origami sesuai dengan pola pre - folded geometri crash box pola origami. Hal ini bisa d lihat pada gambar 7 secara keseluruhan, bahwa bukling sesuai dengan pola pre - folded dari crash box pola origami.

\section{KESIMPULAN}

1. Semakin besar momen inersia luasan penampang crash box, semakin besar kemampuan menyerap energi. Momen inersia luasan penampang sebanding dengan nilai kekakuan crash box, dimana kekakuan yang meningkat menghasilkan kemampuan menahan gaya yang semakin besar dengan deformasi yang semakin kecil. Semakin besar kemampuan menahan gaya yang bekerja pada crash box maka besar energi yang mampu diserap juga semakin besar.

2. Semakin banyak segmen (M) pada crash box pola origami maka semakin besar pula penyerapan energi, namun harus di imbangi dengan besarnya luas penampang dan momen inertia pada crash box tersebut, karena jika tidak sesuai segmen 
dan momen inertia pola pre - folded tidak dapat berfungsi secara maksimal.

\section{DAFTAR PUSTAKA}

[1] World Health Organization (WHO), 2015, The Global Report on Road Safety 2015. Laporan WHO/NMH/NVI/15.6.

[2] X. Zhang, G. Cheng, Z. You, H. Zhang, Energy absorption of axially compressed thinwalled square tubes with patterns, Thin-Walled Struct. 45 (2007) 737-746.
[3] Zhang, X., dan You, Z., 2014. Energy Absorption of Thin-Walled Square Tubes With a Prefolded Origami Pattern-Part I: Geometry and Numerical Simulation. Journal of Applied Mechanics Vol. 81.

[4] Kusyairi, Imam, Moch. Agus Choiron dan Anindito Purnowidodo, 2015. Pengaruh Variasi Desain Crash Box Pola Origami terhadap Kemampuan Penyerapan Energi. Jurnal Rotor Uneversitas Negeri Jember. 